\title{
An Experimental Study on Deformation Fractures of Fissured Rock around Tunnels in True Triaxial Unloads
}

\author{
Meng Wang, Zheming Zhu, and Jun Xie \\ Department of Engineering Mechanics, Sichuan University, Chengdu 610065, China \\ Correspondence should be addressed to Zheming Zhu; zhuzm1965@163.com
}

Received 12 December 2014; Accepted 9 April 2015

Academic Editor: José L. Ocaña

Copyright (C) 2015 Meng Wang et al. This is an open access article distributed under the Creative Commons Attribution License, which permits unrestricted use, distribution, and reproduction in any medium, provided the original work is properly cited.

Joints and cracks are frequently encountered in underground rock mass. During the process of tunnel excavations or other underground construction, the rock will be exposed suddenly, and such sudden unloading process will cause crack expansion and destabilize the rock structure. In order to investigate the crack behaviour during this process, a true triaxial loading apparatus with a computer-controlled electrohydraulic servosystem was established, and a series of true triaxial loading and unloading experiments was conducted by using concrete specimens containing inclined cracks with inclinations of $15^{\circ}, 30^{\circ}, 45^{\circ}, 60^{\circ}$, and $75^{\circ}$. The stressstrain behavior and the failure property of rock models during unloading process were obtained, and, additionally, the coefficient of brittle stress drop was investigated. The uniaxial compression tests were simulated by using finite element method.

\section{Introduction}

Tunnels constructed for road traffic and mineral mining in China can reach depths of 1000-2000 m. Deep roadway excavation usually results in unidirectional or two-direction unloading, which can weaken the stability of the surrounding rocks, leading to rock damage, typically unloading damage $[1,2]$. Deep roadway excavation is a high-stress unloading process and may cause severe expansion of the rock in the unloading direction. The damage occurs mainly as tension fractures, as well as tensional shear fracture and shear fracture [3].

The failure characteristics of basalt, granite, and sandstone under unloading conditions have been studied extensively [4-7]; D. Huang and R. Q. Huang [8] examined the brittle stress drop of granite under equal triaxial confining pressure. Research on the related unloading failure mechanism based on damage-fracture mechanics is in progress to establish a complete stress-strain model under unloading conditions, including the nonlinear strengthening stage, stress drop stage, and strain softening stage [9].

Underground rock mass is subjected to three-direction loads, and they are not the same due to many factors involved, such as the geological structure, the nearby volcanic eruptions, or earthquakes. Joints and cracks are frequently encountered in the underground rock mass, and such cracks usually play a dominant role in the stability of brittle material structures. During the process of rock excavation, the cracks will be exposed and the state of stresses to which the cracks are subjected will alter, and subsequently, the cracks may propagate and may lead to disasters, such as rock burst. Therefore, it is necessary to study the behaviors of cracks during the unloading process.

Zhu et al. [10-15] conducted a number of studies on fracture criteria for a single crack and collinear cracks under compression loading conditions, but the crack behavior during the unloading process has not been focused. D. Huang and R. Q. Huang [8] conducted experiments to study the evolution of central fracture transformation and extension under equal confining pressure and unloading conditions. $\mathrm{Xu}$ and Jiang [16] discussed rock transformation and destruction in different loading stress paths based on a true triaxial experiment, and simulations of rock multistress path evolution under high ground stress were performed by Chen and Feng [17]. True triaxial experiments can simulate several stress paths and represent the complicated underground working environment of a mine. Underground excavation is dangerous because of the existence of cracks in the surrounding rock. Based on the photoelastic experimental method, Wang et al. [18] investigated the stress intensity factors of cracks 
surrounding tunnels with variable fracture inclination and discussed the mechanisms of unstable tunnel destruction caused by cracks. However, the unloading behavior of tunnels has not been addressed.

In this study we carried out triaxial unloading failure experiments by using a true triaxial loading device which is a computer-controlled electrohydraulic servo system. A group of physical models with different inclination angle cracks close to the unloading surface was conducted and was loaded by the true triaxial device. The stress-strain characteristics and failure property of the rock models with different inclination angle cracks during unloading process were obtained. Additionally, the coefficient of brittle stress drop based on these physical models was determined.

\section{Experiment}

2.1. Preparation of Physical Models. The materials of lime, cement, and silver sand at a ratio of $4: 7: 11$ were used to construct the physical models. Hardened lime is brittle but has lower surface density and low strength; hardened cement has lower brittleness but high strength. Using cement and lime as gel materials creates a model that is brittle like rock and also of high strength and elasticity. The model size was $150 \times 150 \times 300 \mathrm{~mm}$, the dry density $\rho$ was about $2750 \mathrm{~kg} / \mathrm{m}^{3}$, and the regular triaxial experiment elasticity $E$ was $2.4 \mathrm{GPa}$, with a Poisson ratio $v$ of 0.23 .

Five different models were created with crack inclinations of $15^{\circ}, 30^{\circ}, 45^{\circ}, 60^{\circ}$, and $75^{\circ}$; each model was made of six materials with a crack length of $50 \mathrm{~mm}$. The spatial relationship is shown in Figure 1. To form the crack, the model material was poured over a $0.2 \mathrm{~mm}$ thick rigid plastic film that represented the crack. When the desired shape and strength were obtained, the material was heated and the plastic film was removed. When the material cooled, the crack closed naturally.

The specimens used in the experiment were large; therefore, joints and cracks often occur in the interior of the specimen, affecting the experimental results. Hence, a special processing method was used that is suitable for analyzing naturally closing cracks. The method uses the thermal expansion and contraction properties of the material. A cutting method is used to create the cracks in the rock specimens, which results in a certain distance between the faces of crack; this affects the curve of the vertical axial stress versus strain. The mechanical properties of the specimens are similar to those of rock and the parameters of density and $E$ are very close, as shown above.

2.2. Loading/Unloading Path. In the experiment, a true triaxial experimental apparatus was established by using computer-controlled electrohydraulic servo system, which was different from the MTS test machine [19]. The position of the model under load testing is shown in Figure 2. The lateral loads were hydraulic loads. The testing equipment measures and records the surface pressure and displacement of the specimens.

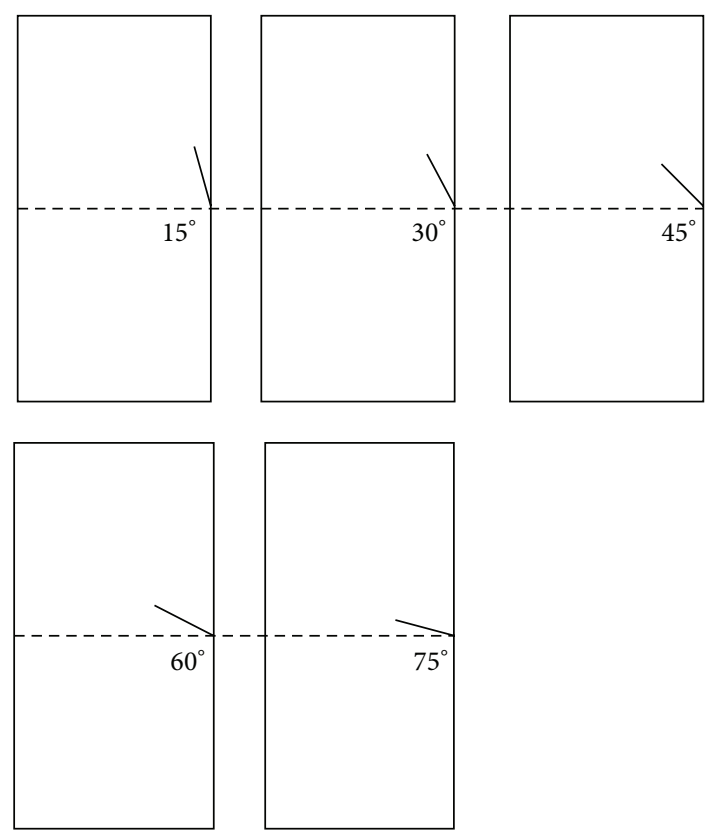

FIgURE 1: Diagram of the testing models.

The feasibility of the testing method was first verified under loading and unloading conditions. Loading the specimens causes the cracks to extend and leads to destruction of the specimen. The experiment included two tests, a reference test and an unloading test, to confirm that material crack extension and connection are caused by unloading. The specific plan is as follows.

2.2.1. Reference Test. (a) Slowly add triaxial pressure to the designed load (15.6 MPa in the axial direction, 6.5 MPa in the lateral direction, and $5.7 \mathrm{MPa}$ to the unloading surface). The vertical axial compression pressure controls the displacement (at a loading rate of $0.017 \mathrm{~mm} / \mathrm{s}$ ); the confining pressure controls the stress (at a loading rate of $0.03 \mathrm{MPa} / \mathrm{s}$ ). (b) Maintain these conditions for $30 \mathrm{~s}$. (c) Slowly unload in the axial direction at an unloading rate of $0.017 \mathrm{~mm} / \mathrm{s}$. Once reaching zero, unload the triaxial pressure at an unloading rate of $0.03 \mathrm{MPa} / \mathrm{s}$.

2.2.2. Unloading Test. (a) Slowly add triaxial pressure to the designed load (15.6 MPa in the axial direction, 6.5 MPa in the lateral direction, and $5.7 \mathrm{MPa}$ to the unloading surface). The vertical axial compression pressure controls the displacement (at a loading rate of $0.017 \mathrm{~mm} / \mathrm{s}$ ) and the confining pressure controls the stress (at a loading rate of $0.03 \mathrm{MPa} / \mathrm{s}$ ). (b) Maintain these conditions for $30 \mathrm{~s}$. (c) Quickly unload to the unloading surface at an unloading rate of $2 \mathrm{MPa} / \mathrm{s}$ while maintaining all the other conditions at their original state.

Upon loading, increase the pressure on the top surface, the excavated face, and the side of the model while constraining the other sides by normal displacement (Figure $2 ; \sigma_{3}$ is the load of the excavated face).

Comparing the two tests for the same crack angle we see that, in the reference test, the materials remain intact after 

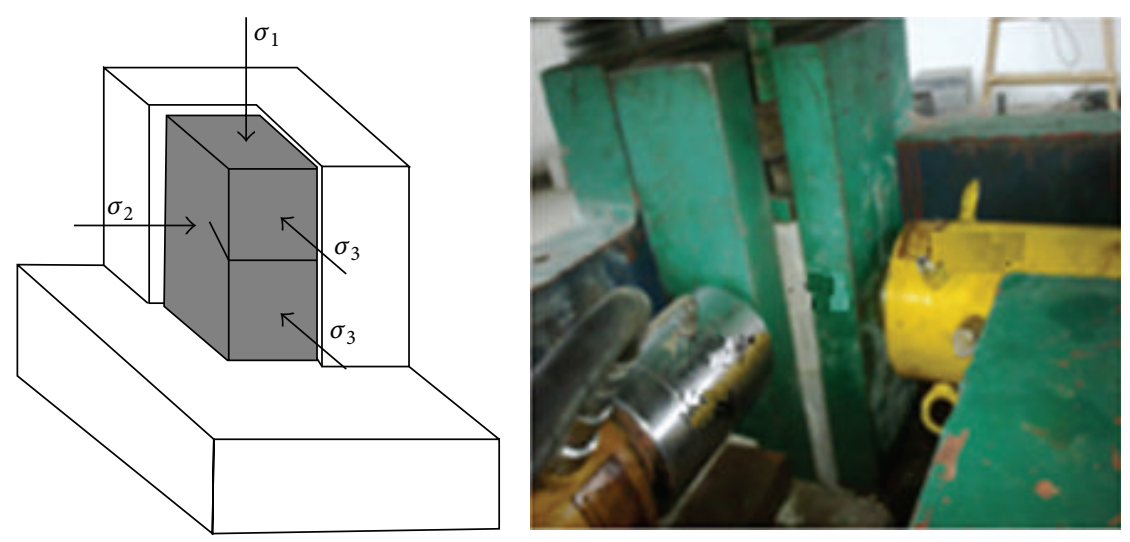

FIGURE 2: Diagram of load of testing model.

unloading and are in a state of densification, with no crack extension. However, in the unloading test, the materials are destroyed. This indicates that the extension and merging of the cracks are indeed caused by unloading.

\section{Numerical Simulation and Analysis}

Since the studies by Griffith [20] showed the propagation of crack instability and the growth criterion introduced by Irwin [21] based on the stress intensity factor, fracture theory has undergone significant development. However, previous studies were limited to simple fracture behavior. Theoretical models that examined the mechanism for crack initiation, expansion, and coalescence were established in recent years with the development of experimental techniques and computer technology. This paper presents a comparison of the simulation of uniaxial compressive damage and true triaxial unloading failure by using a combination of experimental and numerical simulation.

The paper uses the finite element software ANSYS to analyze and simulate crack initiation, expansion, and coalescence under uniaxial compression by using the theory based on the overall failure criterion of rock energy dissipation [22]. For the two-dimensional model, $\sigma_{2}=0$. Thus, the formula found in the literature reduces to the following formula:

$$
\begin{aligned}
& \sigma_{c}^{3}=\left(\sigma_{1}-\sigma_{3}\right)\left(\sigma_{1}^{2}+\sigma_{3}^{2}-2 \nu \sigma_{1} \sigma_{3}\right), \\
& \sigma_{t}^{3}=\sigma_{3}\left(\sigma_{1}^{2}+\sigma_{3}^{2}-2 \nu \sigma_{1} \sigma_{3}\right) .
\end{aligned}
$$

The model uses a crack angle of $45^{\circ}$ and uniaxial compression as the boundary condition (Figure 3 ).

The numerical results show that the expansion mode of the crack, combined with predictive modeling based on fracture mechanics theory, is similar to that observed in the uniaxial compression test. In particular, the trajectories of the preexpansion mode are close to each other (Figure 4). These results, however, are quite different from the experimental results under triaxial unloading conditions (Figure 5). Under unloading conditions, it is difficult to use the existing and established theories to discuss and analyze the damage.

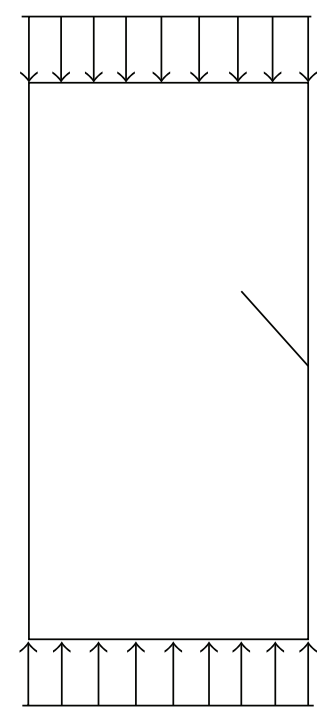

FIgURE 3: The numerical simulation models.

\section{Analysis of Experiment Result}

4.1. Stress-Strain Characteristic Curve under Unloading Condition. The experimental results were processed by the Origin software package to construct the stress-strain curves which were then smoothed. Figure 6 shows typical complete axialdirectional stress-strain curves under unloading conditions with crack inclination of $15^{\circ}, 45^{\circ}$, and $75^{\circ}$. During the initial loading stage, the downward curve $(\mathrm{OA})$ is obvious and presents a typical densification. As the crack angle becomes wider, the axial nominal strain generated when the crack completely closes increases. Therefore, as the crack becomes bigger, the densification becomes more obvious. This process is a reflection of the crack close-up in the loading phase. Before reaching the peak value of the axial-directional stress, the curve shows nonlinear deformation, but no yield platform. Judging from the after-peak curve, in the unloading phase, the axial-directional stress falls quickly to the residual strength level, with a sharp curve slope and small axialdirectional deformation. It shows clear characteristics of 


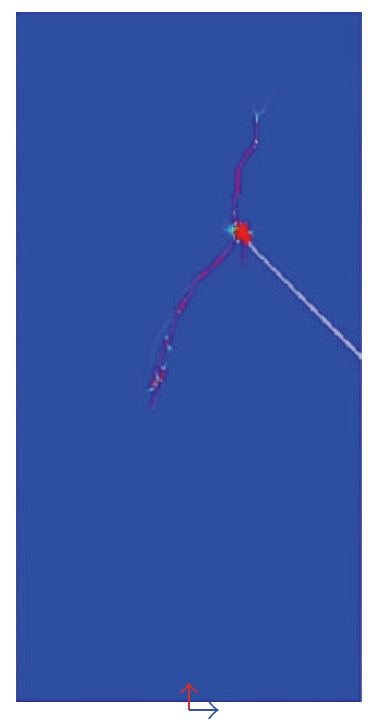

(a)

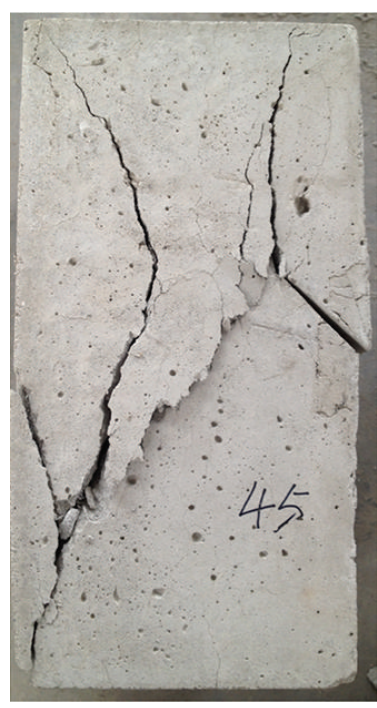

(b)

FIGURE 4: Failure of fissured rocks: photos and numerical simulation. Numerical simulation (a) and uniaxial compression test (b).

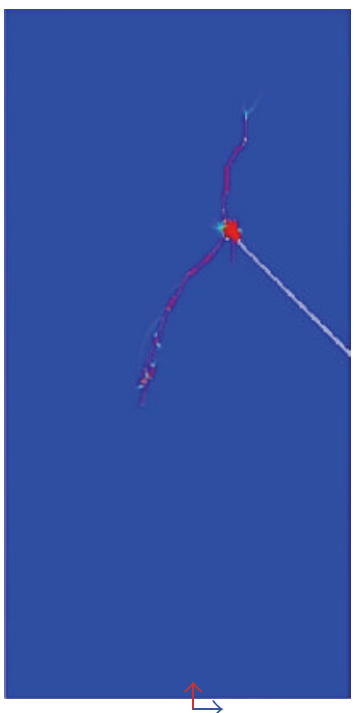

(a)

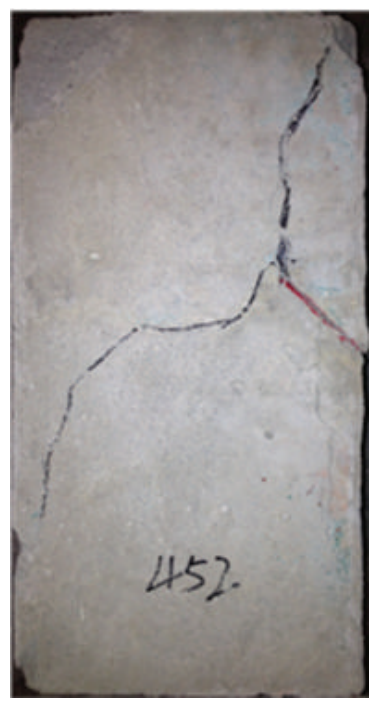

(b)

FIGURE 5: Failure of fissured rocks: photos and numerical simulation. Uniaxial compression test (a) and true triaxial unloading test (b).

brittle stress drop. In addition, for the models with a large inclination, the curve shows an abrupt change. When the axial-directional stress falls to residual strength level, the destruction is rapid and produces a large sound.

4.2. Failure Characteristics. Figure 7 shows a typical failure form and its corresponding sketch. The different crack propagation forms indicate that during the test the crack expansion consists of both tensional shear failure and shear failure. When the crack angle is set at $15^{\circ}$, a pair of tensional fractures appears on the crack tip, with no shear fractures around. During the unloading process, tensional fractures are observed; then shear fractures appear away from the unloading surface. During the entire process, preliminary unloading causes expansion along the unloading direction, and the unloading surface protrudes outward. Meanwhile, in Figure 7, the regional fracture in the red circle connects with the unloading surface, producing a spalling failure. At a later stage, the material generates a perfoliate fracture (besides the original fracture expansion) along the axial direction. When the crack angles are set at $30^{\circ}$ and $45^{\circ}$, at the initial stage, tensional failure occurs at the fracture tip and expands upward along the unloading surface, and the fracture expands inward at the bottom. The two fractures connect and create a macro failure. Impacted by unloading, the fracture expansion 


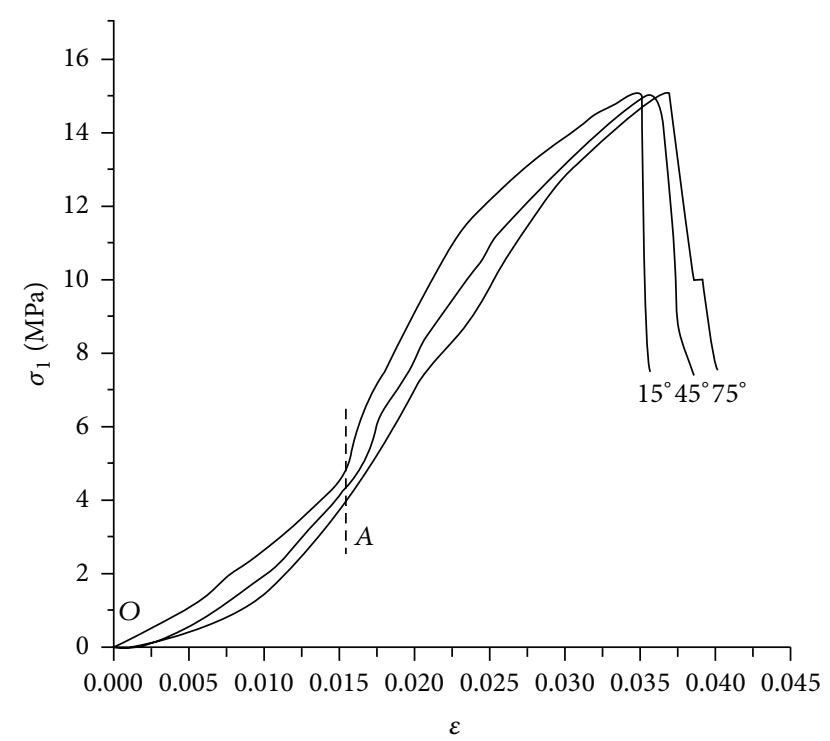

FIGURE 6: Vertical axial stress versus strain under unloading.

is parallel to the unloading surface. When the crack angles are set at $60^{\circ}$ and $75^{\circ}$, tensional failure appears at the initial stage and expands upward. At the same time, the fracture expands inward at the lower part. The two fractures connect and create a macro failure.

In conventional materials, the material is considered as ductile material when it has large deformation but is not broken. Otherwise, it is considered as brittle material. Brittleness and ductility are mainly composed of methods of rock disintegration to distinguish [23]. The rupture and yield are seen as brittle failure and ductile failure, and the strain and the profile of damage can be used as the main control standards.

From Figure 6, the strain of the specimen at failure can be observed, and Heard [24] uses 3\% and 5\% for boundaries to distinguish brittle and ductile rock. In this experiment, the strain changes from $3.5 \%$ to $4.1 \%$, and it illustrates the tendency from brittle to ductile transition.

The above results show that the bigger the crack angle, the greater the failure. During the unloading process, fractures generated at the initial stage join; this is especially obvious for the models with crack inclinations of $60^{\circ}$ and $75^{\circ}$. Moreover, the direction of the penetrating crack changes from its original direction; as the unloading progresses, the crack's extended fracture tends to align with the axial direction. Thus, during underground excavation, when encountering cracks and joints that are almost parallel to the excavating direction, shotcrete stabilization should be applied to avoid rock spalling rather than using anchors; when encountering cracks and joints that are perpendicular to the excavation direction, anchor bolt support should be applied to prevent larger cracks from developing.

In the relevant reference [25], the zonal disintegration phenomena were clearly showed by unloading the $\sigma_{3}$ stress. As shown, there was a certain distance between the failure
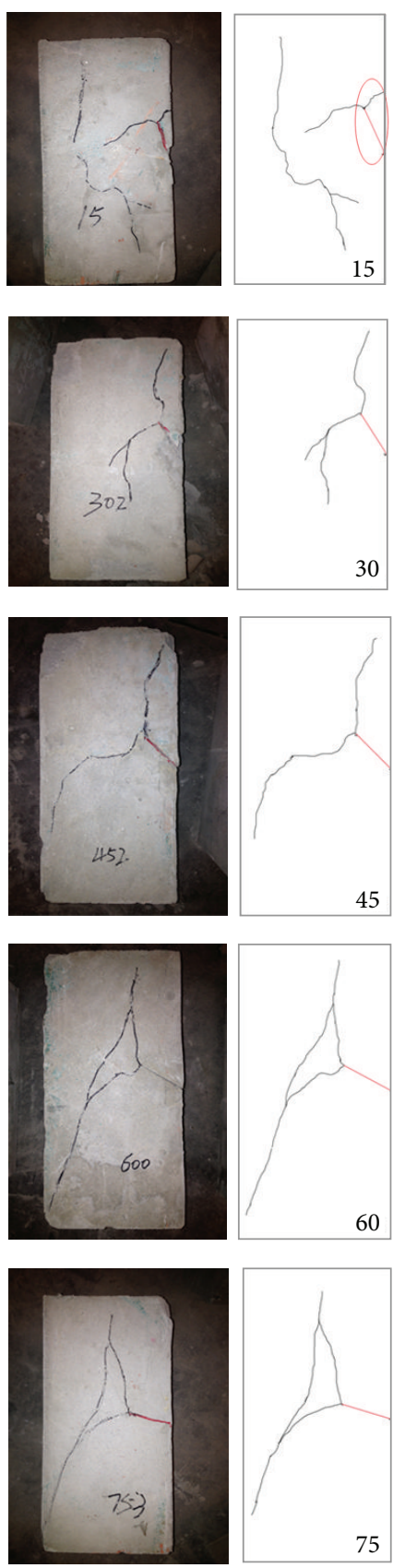

FIGURE 7: Failure of fissured rocks: photos and diagram.

surface and the excavation face. The condition of the reference is equivalent to the specimen containing an inclined crack with inclination of $90^{\circ}$. In this paper, the specimen containing an inclined crack with inclination of $75^{\circ}$ has shown the zonal disintegration phenomenon. The comparison shows the experiments were significant, and they were right, as shown in Figure 8. The result in this paper was shown as Figure $8(\mathrm{a})$, and the result of the reference was shown as Figure 8(b).

4.3. Comparison Characteristics. Figure 9 shows a comparison of the triaxial failure modes and uniaxial test failure 


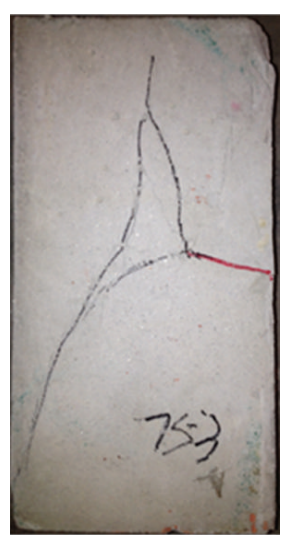

(a)

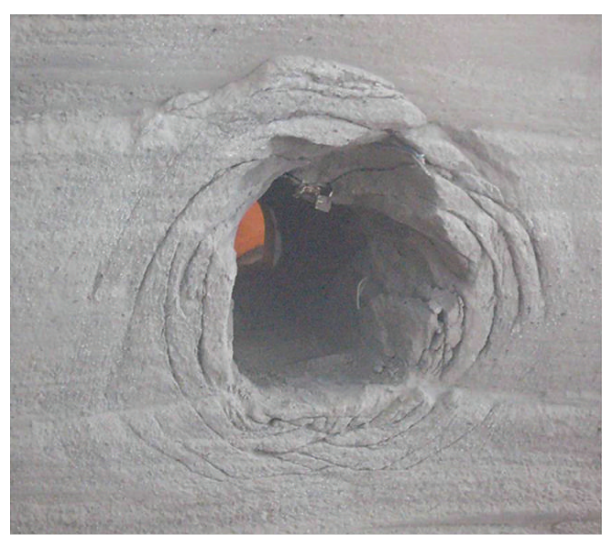

(b)

FIgURE 8: The comparison of the results between this paper and the reference.

modes. In the uniaxial experiment, both $\sigma_{2}$ and $\sigma_{3}$ are zero. The fractures that lead to failure all pass through the fracture tip, and the overall fracture direction is close to that of the cracked surfaces. The shear effect is significant and causes a serious failure which leads to secondary failure. The triaxial failure is a unidirectional failure caused by dilatation; as the inclination angle increases, delamination failure appears parallel to the unloading surface. In the experiment, the phenomenon is clearly observed for inclinations of $60^{\circ}$ and $75^{\circ}$. In unidirectional unloading, because the energy is released in the same direction, rapidly falling rock fragments appear when high energy is released at a small crack angle. Unidirectional unloading is commonly seen in excavation, and there is a considerable difference between the unloading experiment and the single-axis compression failure test, reflecting the significance of true triaxial unloading experimental research.

\subsection{Coefficient of Brittle Stress Drop}

4.4.1. Parameter Confirmation Method. Using plastic potential theory, Ge [26] derived the brittle stress drop process of the stress nonvertical drop model. Shi et al. [27] combined the overall stress-strain curve of a typical rock compression test with observed brittleness as shown in Figure 10 and propose the coefficient of brittle stress drop $R$ :

$$
R=\frac{b}{a}
$$

where $a$ and $b$ are strain-related parameters, $a=\varepsilon_{p}-\varepsilon_{M}, b=$ $\varepsilon_{B}-\varepsilon_{p}$, and $\varepsilon_{p}$ is the axial strain of peak intensity point; $\varepsilon_{B}$ is the axial strain of the residual intensity point; and $\varepsilon_{M}$ is the difference between the corresponding initial elastic loading strain and the residual intensity stress value. The ideal brittleness model is the special situation, where $b=0$. Equation (2) indicates that the smaller the $R$ is, the stronger the failure character of the rock stress brittleness is.

4.4.2. Parameter Variation Characters in the Unloading Test. Studies on the relationship between the coefficient of brittle stress drop of intact rock and the uniaxial/equal triaxial confining pressure and general confining pressure include those of Huang et al. [5] and Chen and Feng [17]. However, during underground excavations, faults and joints will often be encountered, and the coefficient of brittle stress drop will be related to the crack angle. Under the same initial stress and confining pressure, the coefficient of brittle stress drop and the characteristic parameters in the unloading test should be a function of crack angle, as in

$$
R(\theta)=\frac{\varepsilon_{B}(\theta)-\varepsilon_{P}(\theta)}{\varepsilon_{P}(\theta)-\varepsilon_{M}(\theta)}
$$

The axial-directional stress rapidly falls to residual strength levels. This feature is caused by the rapid expansion and connectivity of the cracks. The brittle fracture properties of rock specimens and the damage and fracture mechanism of brittle rock and their strength characteristics were observed by Costamagna et al. [28] and Golshani et al. [25]. However, few studies on the properties of brittle fracture under triaxial unloading conditions have been conducted. The coefficients of brittle stress drop can significantly affect the degree of brittleness of the material and it is conducive to improve the nonideal elastic-brittle-plastic model to account for the coefficients of brittle stress drop. Further, it can provide a better theoretical basis for numerical simulations of rock mechanics.

The characteristic parameters of each unloading test material determined during our experiments are presented in Figures 11-13. Figure 12 shows that as the crack inclination angle increases, the axial strain at the peak intensity point tends to lie more along the axial direction. This is mainly because of the compaction at the initial stage. There are gaps between cracks; when the angle between the crack and the horizontal axis is wider, the projected area along the vertical axis becomes larger, which leads to a larger variation upon closing. Figure 11 shows that as the crack inclination angle increases, the residual intensity point of the specimen tends to increase along the axial direction (mainly influenced by the peak intensity point). 

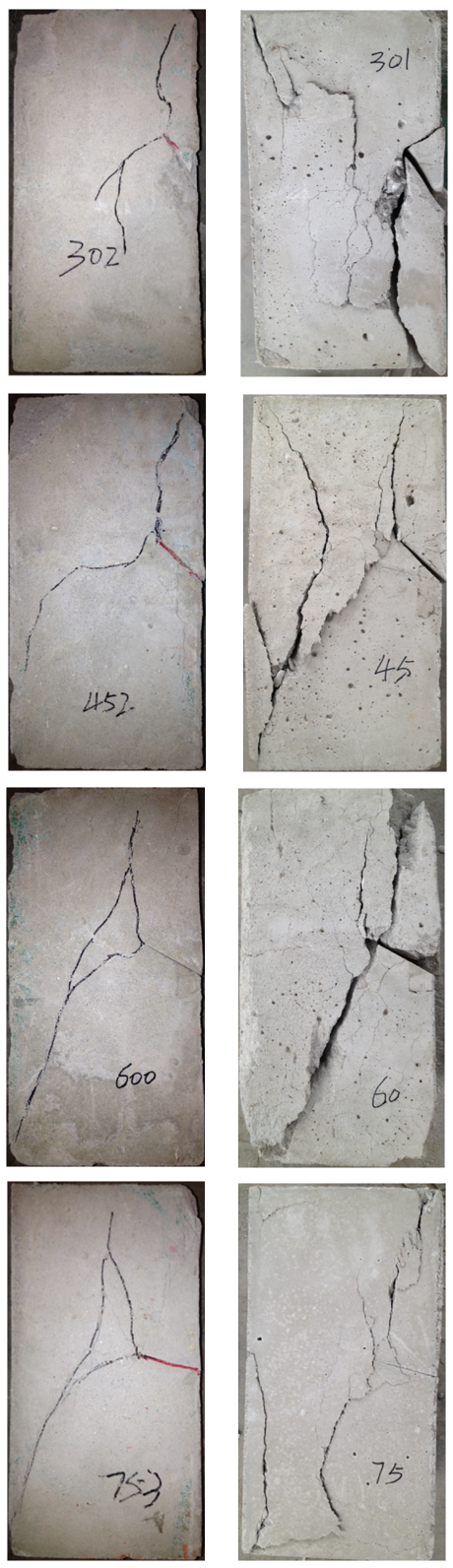

(b)

FIGURE 9: Failure of fissured rocks. True triaxial unloading test (a) and uniaxial compression test (b).

4.4.3. Variation of the Brittle Stress Drop Parameters. The author used a quadratic equation to fit the test results (Figures 11-13) to a regression curve, as follows:

$$
\begin{gathered}
\varepsilon_{B}=-0.000820 x^{2}+0.143180 x+33.784653, \\
\varepsilon_{P}=-0.000187 x^{2}+0.052498 x+34.039389, \\
\varepsilon_{M}=0.000459 x^{2}+0.014482 x+17.718801 .
\end{gathered}
$$

Combined with (3) $R$ can be obtained as

$$
R(\theta)=\frac{-633 * \theta^{2}+90682 * \theta-254736}{-646 * \theta^{2}+38016 * \theta+16320588} .
$$

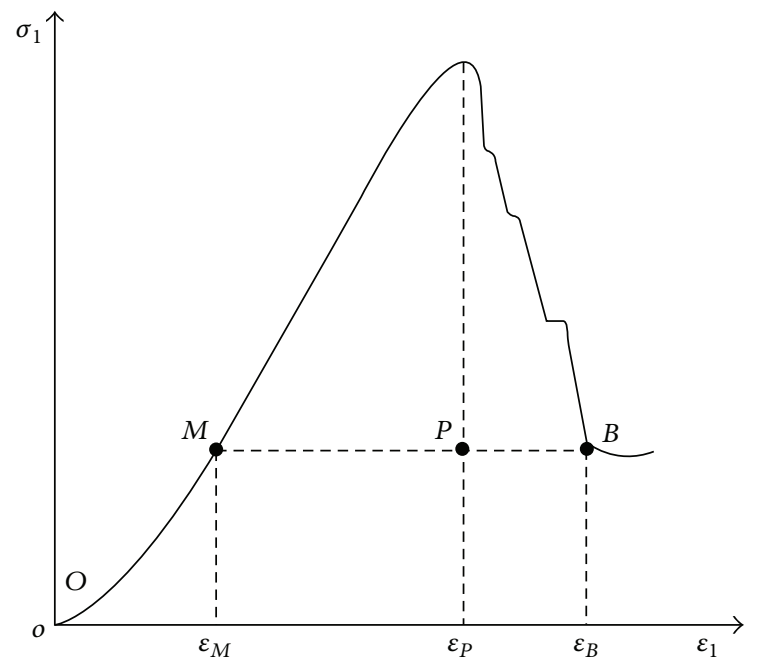

FIGURE 10: Typical complete stress-strain curve of brittle rocks.

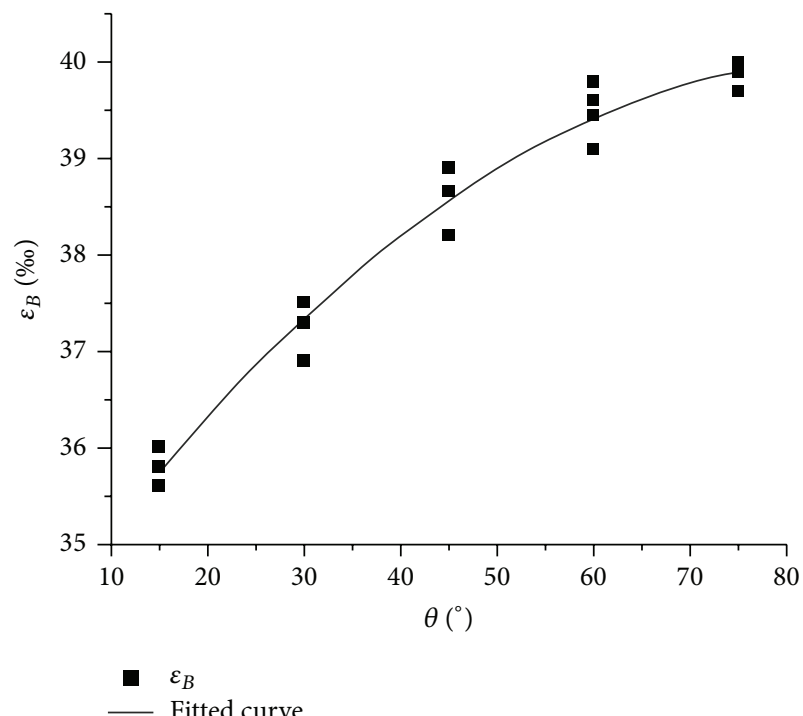

FIGURE 11: Axial strain at residual strength level versus crack orientations.

From (5), the curve of the coefficient of brittle stress drop versus crack orientations was derived (Figure 14). As the crack angle widens the brittle stress drop of the specimen increases, suggesting a transformation from brittle to ductile state. Hence, in underground excavation, as the angle between the crack and the unloading surface becomes smaller, the brittle failure becomes more obvious. Simultaneously, brittle failure may suddenly occur. At this point in the excavations, support measures will be required to control the brittle failure. For example, conventional tunnel excavation applies shotcretebolt support and anchors penetrate the cracks.

4.5. Deformation during the Unloading Process. In underground excavation, rock deformation is an important factor for project safety evaluations. Based on unloading test results, 


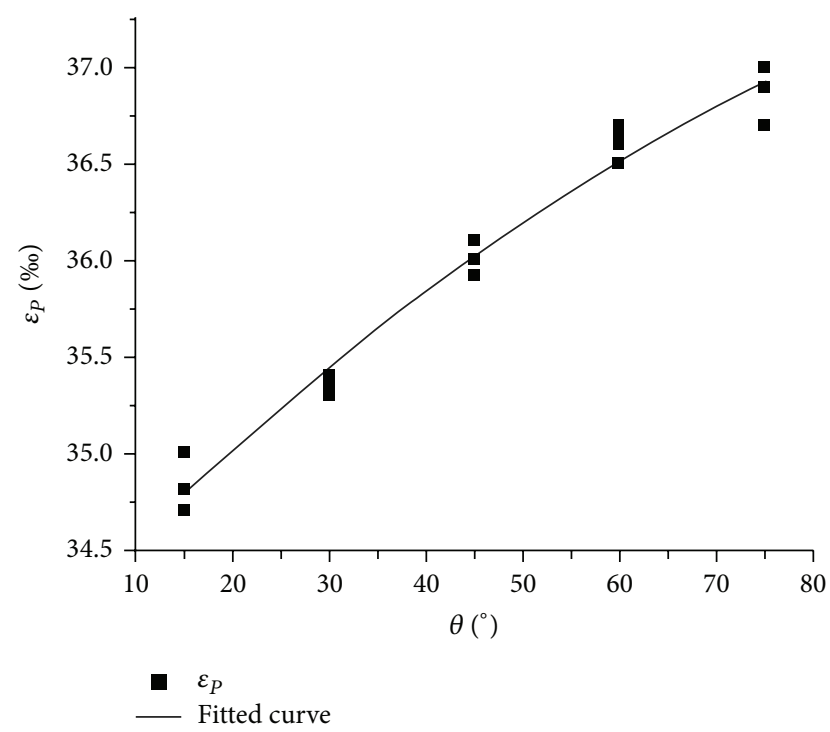

FIgURE 12: Axial strain at peak strength versus crack orientations.

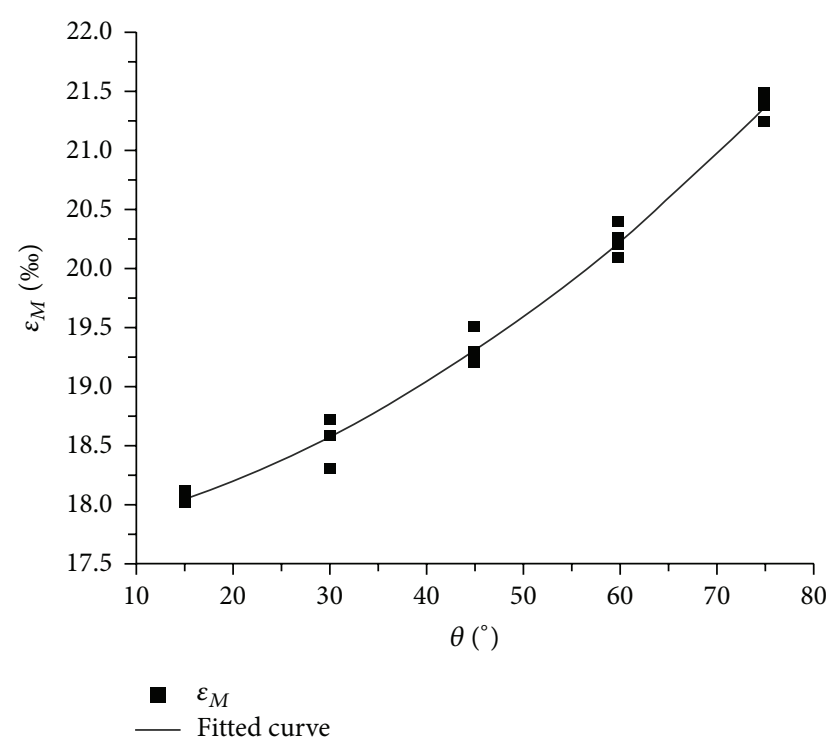

Figure 13: Axial strain at the elastic stage which corresponds to the residual strength versus crack orientations.

this paper studies the unloading deformation of the specimen by the axial-directional strain of the after-peak curve.

Figure 15 shows the unloading deformation versus crack orientations. Here, we define the unloading deformation as the difference between $\varepsilon_{p}$ and $\varepsilon_{B}$.

As the specimen fracture angle increases, the unloading deformation shows an upward trend. The wider the crack angle, the clearer the expansion along the unloading surface. Moreover, the unloading deformation and inclination show

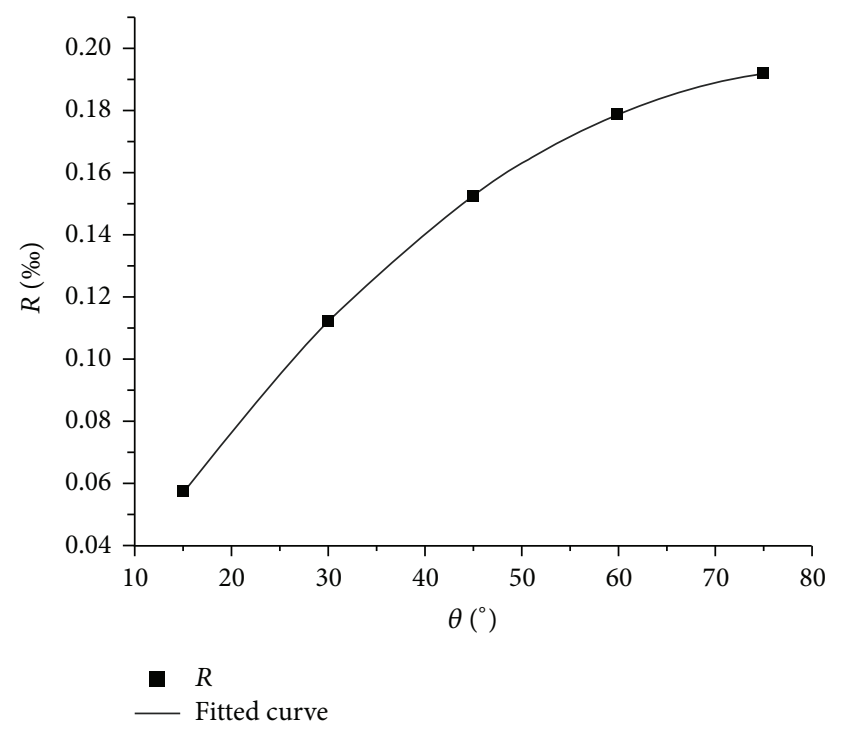

FIGURE 14: Coefficients of brittle stress drop versus crack orientations.

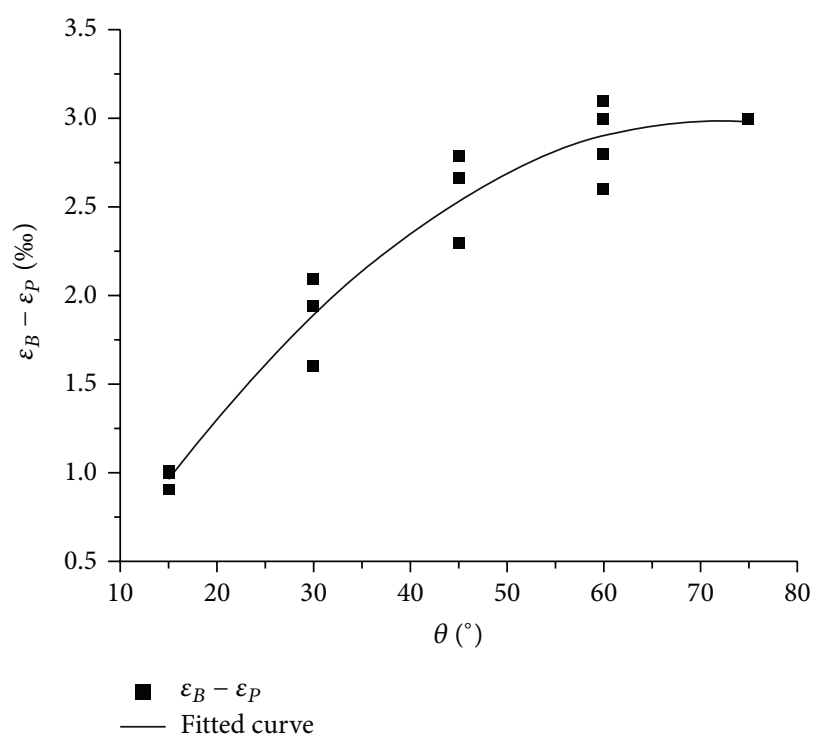

FIGURE 15: Unloading deformation versus crack orientations.

good correlation. The quadratic formula can be fitted to this curve to obtain

$$
\begin{aligned}
y & =-0.0001 x^{2}+0.0013 x-0.0003, \\
R^{2} & =0.9729 .
\end{aligned}
$$

\section{Conclusions}

In this study, an improved true triaxial experimental facility by introducing a computer-controlled electrohydraulic servo system was established, and triaxial unloading experiments were conducted. A deep-buried tunnel was considered, and the cracks near the unloading surface were investigated. 
Under unloading conditions, the rock stress-strain characteristics and the failure features for different inclination cracks were studied, and the following conclusions can be obtained.

(1) During the initial loading stage, the stress-strain curve is concaved and presents typical densification. Before reaching the peak value of the axial-directional stress, the curve shows nonlinear deformation, but no yield platform can be observed.

(2) From the after-peak stage in the unloading curve, the axial-directional stress falls quickly to the residual strength level with a small axial-directional deformation. It shows the characteristics of brittle stress drop.

(3) As the specimen crack inclination angle increases, the unloading deformation increases. The larger the crack inclination angle, the clearer the expansion along the unloading surface. The risk of rock collapse during excavation increases as the inclination angle decreases.

(4) The main form of damage in the failed specimens was tensile failure. The tensile failure characteristics are more obvious in triaxial compression than in uniaxial compression.

(5) As crack inclination angle increases, the axial nominal strain generated when the crack completely closes increases, and the brittle stress drop increases, and the transformation from brittle to ductile state occurs. Hence, in underground excavation, as the crack inclination angle between the crack and the unloading surface is small, the brittle failure will be more obvious.

(6) In the further study, the dynamic unloading process should be considered because the dynamic loading [29-31] is different from the static loading.

\section{Conflict of Interests}

The authors declare that there is no conflict of interests regarding the publication of this paper.

\section{Acknowledgments}

This work was financially supported by the Open Fund of State Key Laboratory of Oil and Gas Reservoir Geology and Exploitation (PLN1202), by the Project of Science and Technology of Sichuan Province (2014JY0002), and by the National Natural Science Foundation of China (51074109).

\section{References}

[1] G. Wu, "Current status and prospects of research on mechanism for unloading failure of engineering rock mass," Journal of Engineering Geology, vol. 9, no. 2, pp. 174-181, 2001.

[2] Z. Y. Zhang, S. T. Wang, and L. S. Wang, Principles of Engineering Geology, Geological Publishing House, Beijing, China, 1994.

[3] J. H. Shen, L. S. Wang, Q. H. Wang, J. Xu, Y. Jiang, and B. Sun, "Deformation and fracture features of unloaded rock mass,"
Chinese Journal of Rock Mechanics and Engineering, vol. 22, no. 12, pp. 2028-2031, 2003.

[4] T. B. Li and L. S. Wang, "An experimental study on the deformation and failure features of basalt under unloading condition," Chinese Journal of Rock Mechanics and Engineering, vol. 12, no. 4, pp. 321-327, 1993.

[5] D. Huang, R.-Q. Huang, and Y.-X. Zhang, "Characteristics of brittle failure and stress drop under triaxial loading and unloading," Journal of Civil, Architectural \& Environmental Engineering, vol. 33, no. 2, pp. 1-6, 2011.

[6] J. L. Li, R. H. Wang, Y. Z. Jiang, J. Liu, and X. Chen, "Experimental study of sandstone mechanical properties by unloading triaxial tests," Chinese Journal of Rock Mechanics and Engineering, vol. 29, no. 10, pp. 2034-2041, 2010.

[7] Y. H. Lu, Q. S. Liu, and Y. H. Hu, "Damage deformation characteristics and its strength criterion based on unloading experiments of granites," Chinese Journal of Rock Mechanics and Engineering, vol. 28, no. 10, pp. 2096-2103, 2009.

[8] D. Huang and R. Q. Huang, "Physical model test on deformation failure and crack propagation evolvement of fissured rocks under unloading," Chinese Journal of Rock Mechanics and Engineering, vol. 29, no. 3, pp. 502-512, 2010.

[9] X. P. Zhou, Q. L. Ha, Y. X. Zhang, J. H. Wang, and K. S. Zhu, "Analysis of localization of deformation and complete stressstrain relation for mesoscopic heterogenous brittle rock materials when axial stress is held constant while lateral confinement is reduced," Chinese Journal of Rock Mechanics and Engineering, vol. 24, no. 18, pp. 3236-3245, 2005.

[10] Z. M. Zhu, "New biaxial failure criterion for brittle materials in compression," Journal of Engineering Mechanics, vol. 125, no. 11, pp. 1251-1258, 1999.

[11] Z. M. Zhu, "An alternative form of propagation criterion for two collinear cracks under compression," Mathematics and Mechanics of Solids, vol. 14, no. 8, pp. 727-746, 2009.

[12] Z. M. Zhu, "Evaluation of the range of horizontal stresses in the earth's upper crust by using a collinear crack model," Journal of Applied Geophysics, vol. 88, pp. 114-121, 2013.

[13] Z. M. Zhu, L. G. Wang, B. Mohanty, and C. Huang, "Stress intensity factor for a cracked specimen under compression," Engineering Fracture Mechanics, vol. 73, no. 4, pp. 482-489, 2006.

[14] Z. M. Zhu, H. P. Xie, and S. Ji, “The mixed boundary problems for a mixed mode crack in a finite plate," Engineering Fracture Mechanics, vol. 56, no. 5, pp. 647-655, 1997.

[15] T. Zheng, Z. Zhu, B. Wang, and L. Zeng, "Stress intensity factor for an infinite plane containing three collinear cracks under compression," Journal of Applied Mathematics and Mechanics, vol. 94, no. 10, pp. 853-861, 2014.

[16] D. J. Xu and N. G. Jiang, "The various stress paths causing deformation and failure in rocks," Rock and Soil Mechanics, vol. 7, no. 2, pp. 17-25, 1986.

[17] J. T. Chen and X. T. Feng, "True triaxial experimental study on rock with high geo-stress," Chinese Journal of Rock Mechanics and Engineering, vol. 25, no. 8, pp. 1537-1543, 2006.

[18] M. Wang, Z. M. Zhu, and L. G. Zeng, "Experimental study on the stress intensity factors of cracks around tunnels," Journal of Sichuan University (Engineering Science Edition), vol. 44, pp. 99103, 2012.

[19] R. G. Deng, X. M. Fu, and J. Xu, "Study of measuring system for triaxial stresses and pore content of rock with MTS uniaxial machine," Chinese Journal of Rock Mechanics and Engineering, vol. 21, no. 6, pp. 892-896, 2002. 
[20] A. A. Griffith, "The phenomena of rupture and flow in solids," Philosophical Transactions of the Royal Society of London Series A, vol. 221, pp. 163-198, 1920.

[21] G. R. Irwin, "Crack extension force for a part-through crack in a plate," Journal of Applied Mechanics, vol. 29, no. 4, pp. 651-654, 1962.

[22] H.-P. Xie, Y. Ju, and L.-Y. Li, “Criteria for strength and structural failure of rocks based on energy dissipation and energy release principles," Chinese Journal of Rock Mechanics and Engineering, vol. 24, no. 17, pp. 3003-3010, 2005.

[23] S. Z. Wang, "Brittle-ductile transition and plastic-flow networks in rocks," Progress in Geophysics, vol. 8, no. 4, pp. 25-37, 1993.

[24] H. C. Heard, "Effect of large changes in strain rate in the experimental deformation of Yule marble," The Journal of Geology, vol. 71, no. 2, pp. 162-195, 1963.

[25] A. Golshani, M. Oda, Y. Okui, T. Takemura, and E. Munkhtogoo, "Numerical simulation of the excavation damaged zone around an opening in brittle rock," International Journal of Rock Mechanics and Mining Sciences, vol. 44, no. 6, pp. 835-845, 2007.

[26] X. R. Ge, "Post failure behavior and a brittle plastic model of brittle rock," in Computer Methods and Advances in Geomechanics, pp. 151-160, A.A. Balkema, Rotterdam, The Netherlands, 1997.

[27] G. C. Shi, X. R. Ge, and Y. D. Lu, "Experimental study on coefficients of brittle stress drop of marble," Chinese Journal of Rock Mechanics and Engineering, vol. 25, no. 8, pp. 1625-1631, 2006.

[28] R. Costamagna, J. Renner, and O. T. Bruhns, "Relationship between fracture and friction for brittle rocks," Mechanics of Materials, vol. 39, no. 4, pp. 291-301, 2007.

[29] Z. M. Zhu, B. Mohanty, and H. Xie, "Numerical investigation of blasting-induced crack initiation and propagation in rocks," International Journal of Rock Mechanics and Mining Sciences, vol. 44, no. 3, pp. 412-424, 2007.

[30] Z. M. Zhu, H. Xie, and B. Mohanty, "Numerical investigation of blasting-induced damage in cylindrical rocks," International Journal of Rock Mechanics and Mining Sciences, vol. 45, no. 2, pp. 111-121, 2008.

[31] Z. M. Zhu, "Numerical prediction of crater blasting and bench blasting," International Journal of Rock Mechanics and Mining Sciences, vol. 46, no. 6, pp. 1088-1096, 2009. 

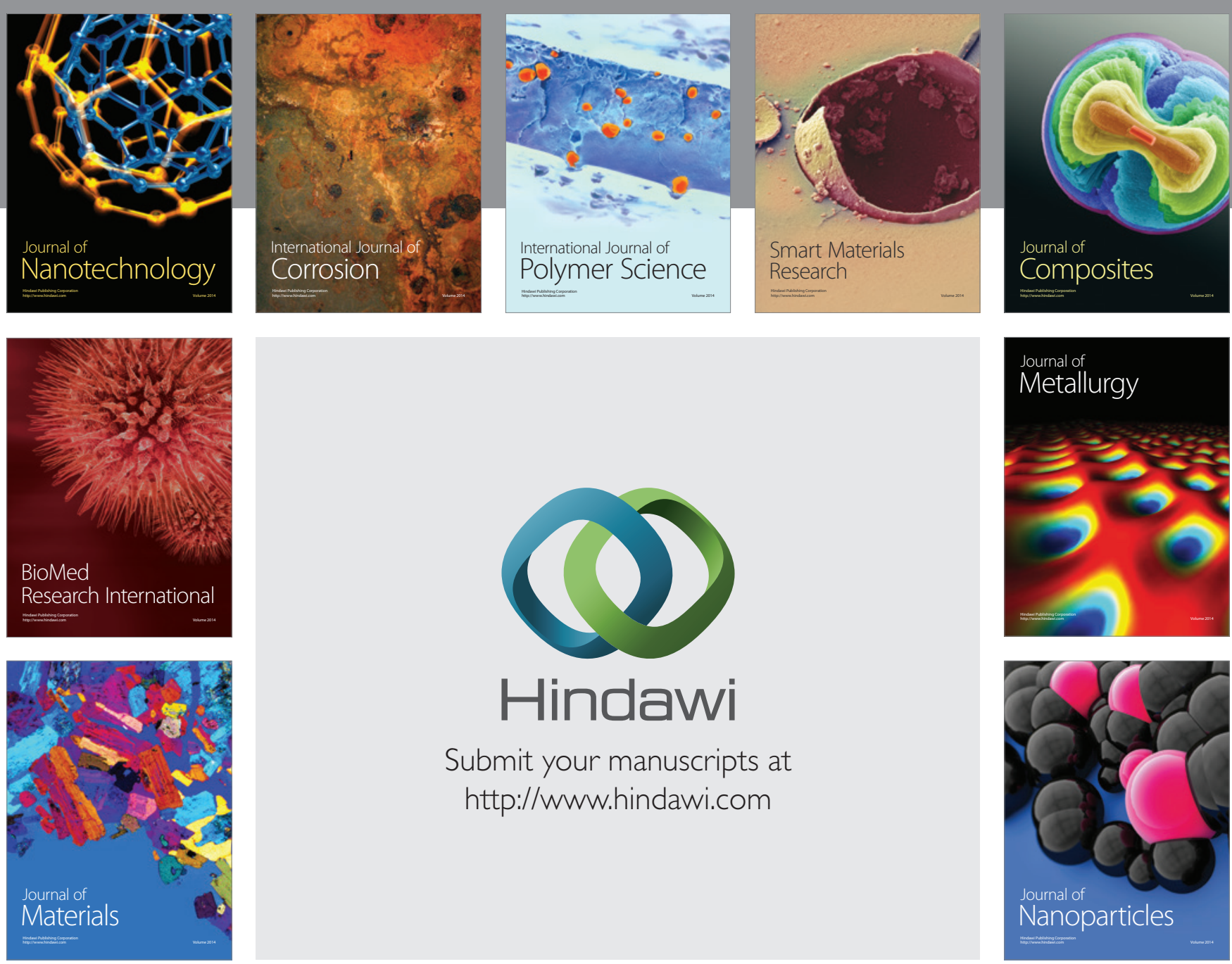

Submit your manuscripts at http://www.hindawi.com
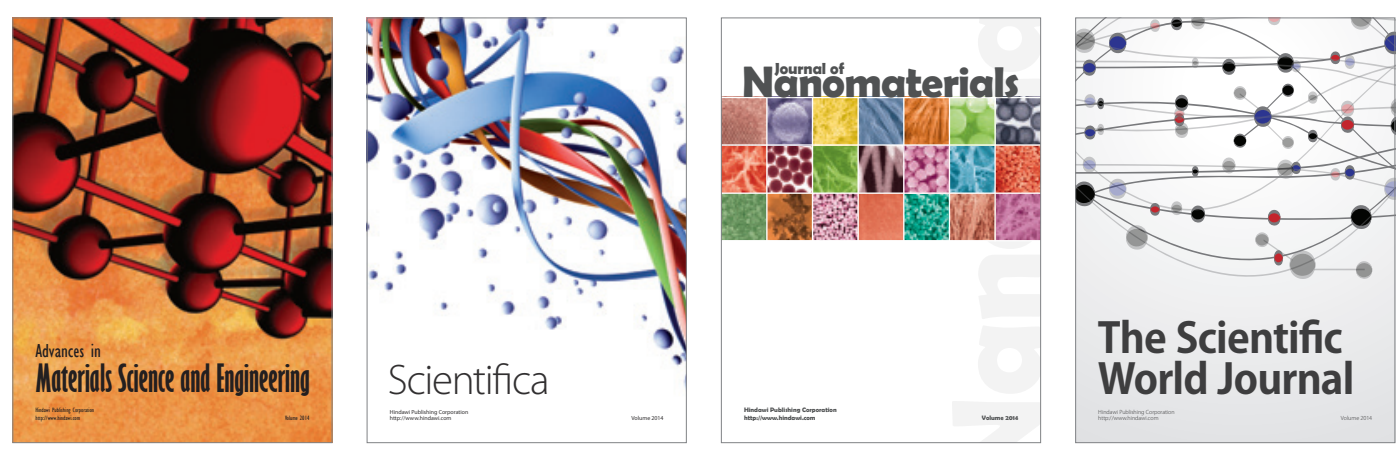

\section{The Scientific World Journal}
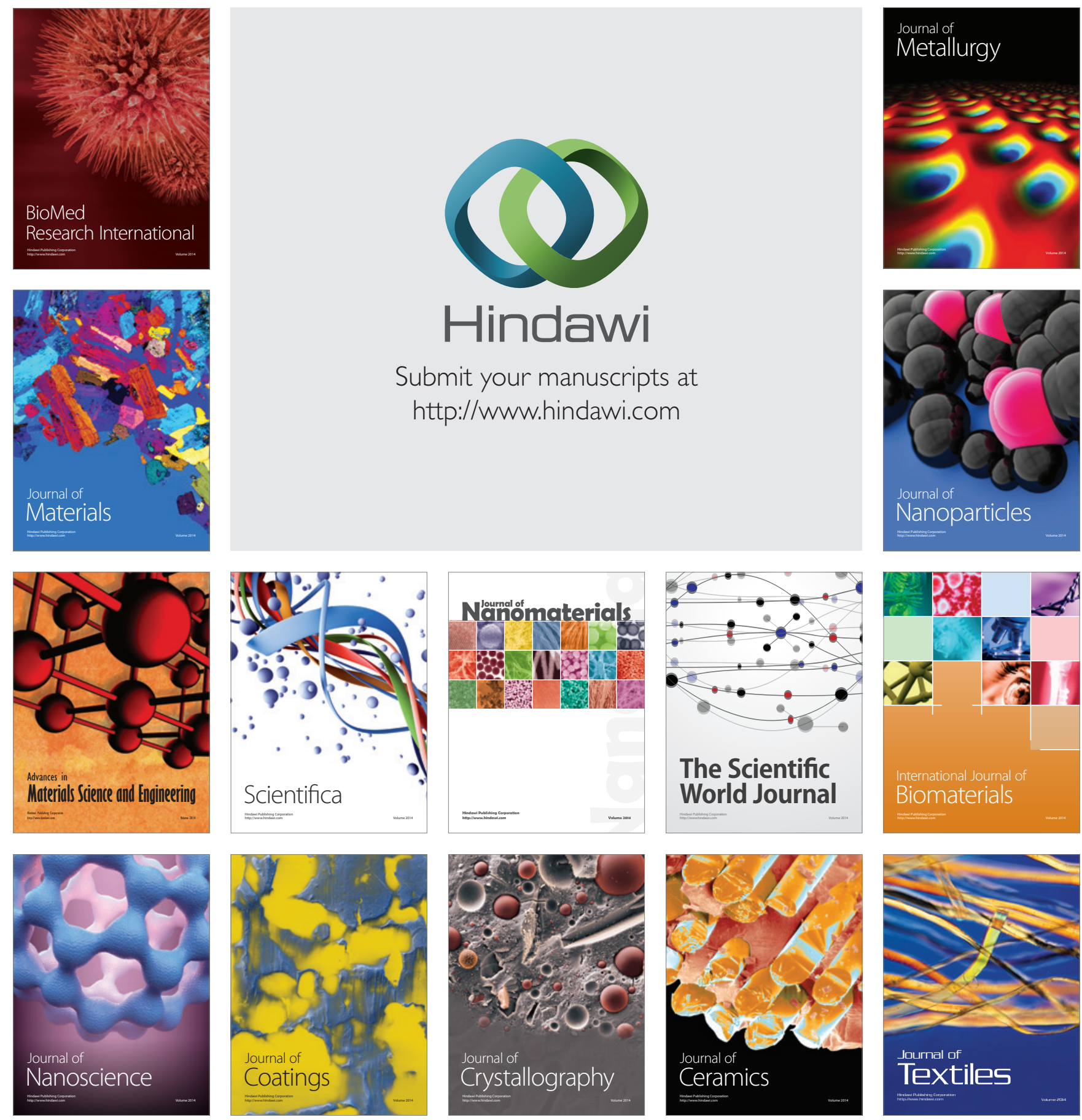